\title{
Drug Interactions With Cyclosporine-Rifampicin-Clarithromycin in a Kidney Transplant Recipient With Mycobacterium Malmoense
}

\author{
Ana Aldea Perona ${ }^{\mathrm{a}, \mathrm{d}}$, Mar García Sáiz ${ }^{\mathrm{b}}$, Lourdes Pérez Tamajón ${ }^{\mathrm{c}}$
}

\begin{abstract}
A 38-year-old kidney transplant recipient was treated with antituberculous drugs due to mycobacterial joint infection due to Mycobacterium malmoense. Three days of starting combined therapy, cyclosporine blood concentration (CBC) decreased a $63 \%$ and was necessary to increase the cyclosporine dose. Clarithromycin was also added and the $\mathrm{CBC}$ and kidney function remained stable until 11 months later. Pirazinamide and isoniazide were withdrawn four months before without any analytical changes but when rifampicin and ethambutol were withdrawn, CBC showed an increase of $377 \%$ and creatinine level was worsened. It was necessary to reduce the cyclosporine dose and renal function improved within 6 weeks. When clarithromycin was discontinued, the CBC decreased a $69 \%$ which motivated gradually increasing the dose. $\mathrm{CBC}$ is liable to change in patients treated with drugs metabolized by cytochrome p450 system, and the effect and magnitude of a multiple interaction is unpredictable. Close monitoring is necessary to adjust the dosage.
\end{abstract}

Keywords: Cyclosporine; Kidney transplantion; Antitubercular agents; Mycobacterium malmoense; Tuberculosis osteoarticular

\section{Introduction}

Drug interactions are widely acknowledged and can interfere

\footnotetext{
Manuscript accepted for publication January 3, 2013

${ }^{\mathrm{a} C l i n i c a l}$ Research Unit, Hospital Universitario de Canarias, Ofra S/N. La Cuesta. La Laguna, Spain

${ }^{\mathrm{b}}$ Clinical Pharmacology Service, Hospital Universitario de Canarias, La Laguna, Spain

${ }^{\mathrm{c}}$ Nephrology Service, Hospital Universitario de Canarias, La Laguna, Spain

${ }^{\mathrm{d}}$ Corresponding author: Ana Aldea, Clinical Research Unit, Hospital Universitario de Canarias, Ofra S/N. La Cuesta. La Laguna, Spain. Email: a.aldea@gmail.com
}

doi: http://dx.doi.org/10.4021/jmc1058w with the clinical management of clinical cases, specially in transplant recipients. This case shows a variety of interactions with a highly educational potential. Cyclosporine, has been widely used as immunosuppressant, is metabolized by intestinal and hepatic cytochrome p450 system and is a substrate of the P-glycoprotein transport system, which results in numerous drug interactions [1].

\section{Case Report}

A 38-year-old man with diabetic nephropathy received a renal transplant in February 1997 for end-stage renal disease. Four years later he was stable with immunosuppressive therapy consisting of prednisone $5 \mathrm{mg} /$ day, mycophenolate mofetil $1.5 \mathrm{~g}$ /day and cyclosporine $200 \mathrm{mg}$ /day; cyclosporine blood concentrations $(\mathrm{C} 0)$ were within the therapeutic range (measured by Fluorescence Polarization Immunoassay-TDXx®, Abbott). But the patient developed panniculitis and aquilea tendinitis in his legs (joint pain, tumidity, functional inability and erythema) and a greater dose of prednisone $(15 \mathrm{mg} /$ day $)$ was administered. The skin lesions and synovitis worsened and progressed to the upper extremities, limiting movement of the right carpo-metacarpal joint. Then he was admitted into hospital with a creatinine plasmatic concentration of 1.9 $\mathrm{mg} / \mathrm{dL}$ and creatinine clearence of $42.41 \mathrm{~mL} / \mathrm{min}$.

After positive Mantoux test and Ziehl-Neelsen stain in joint fluid and synovial membrane biopsy, mycobacterium infection was suspected.

Antituberculosis therapy was started with rifampicin $300 \mathrm{mg} /$ day, ethambutol 1,200 mg/day, pirazinamide 1,750 $\mathrm{mg}$ /day and isoniazid $300 \mathrm{mg} /$ day.

After 3 days of this combined therapy, $\mathrm{C} 0$ of cyclosporine had fallen from $153 \mathrm{ng} / \mathrm{mL}$ to $56 \mathrm{ng} / \mathrm{mL}$ (a decreased by $63 \%$ ); the dose was increased to $300 \mathrm{mg} /$ day (an increase by $33 \%$ ) and clarithromycin $500 \mathrm{mg}$ b.i.d. was also added. $\mathrm{C} 0$ of cyclosporine $(142 \pm 25 \mathrm{ng} / \mathrm{mL})$ and kidney function (creatinine $1.4-1.6 \mathrm{mg} / \mathrm{dL}$ ) remained stable for 7 months with the same treatment. Pirazinamide and isoniazide were withdrawn without any analytical changes. The result of the synovial fluid culture was Mycobacterium malmoense.

Six months later, rifampicin and ethambutol were with- 


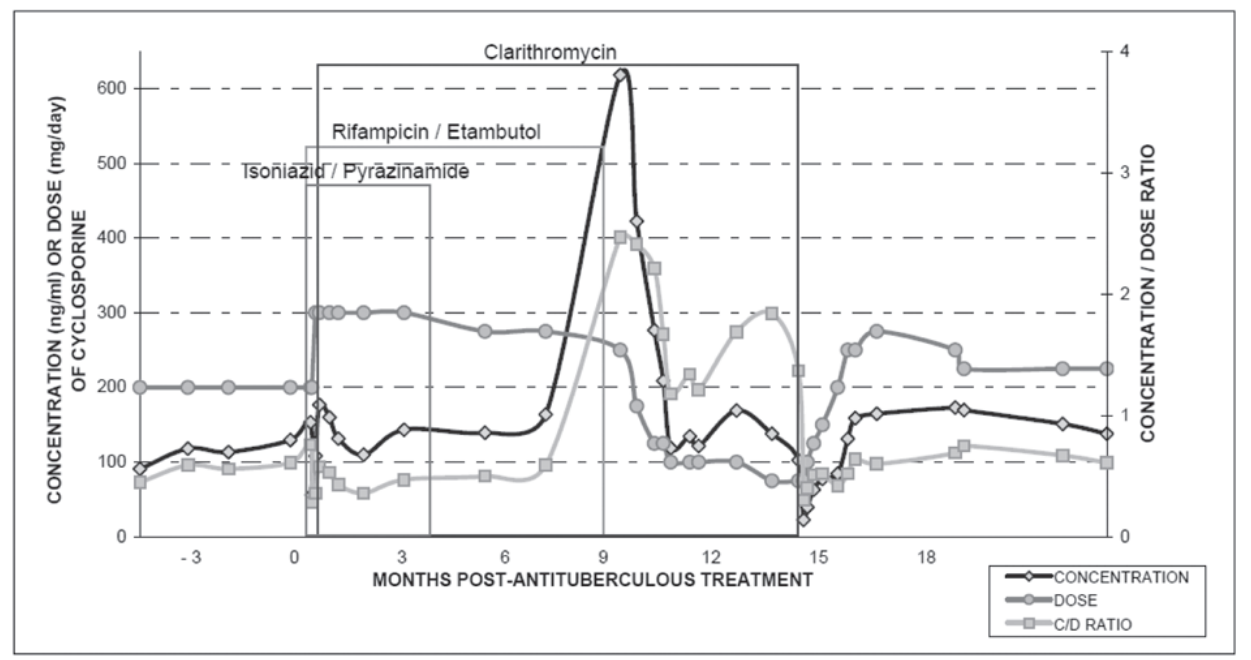

Figure 1. Evolution of cyclosporine concentration and $C / D^{*}$ ratio in multiple drug interactions involving antitubercular agents. ${ }^{*} \mathrm{C}$ : concentration; D: doses.

drawn and clarithromycin was continued. No determinations were performed until fifteen days later when cyclosporine C0 reached $618 \mathrm{ng} / \mathrm{mL}$ (an increase of 377\%) and creatinine level was $2.2 \mathrm{mg} / \mathrm{dL}$. It was necessary to drastically reduce the cyclosporine dose to $100 \mathrm{mg}$ /day to maintain satisfactory blood concentrations and renal function decreased to $1.7 \mathrm{mg} /$ dL within 6 weeks.

One year later, clarithromycin was discontinued; cyclosporine $\mathrm{C} 0$ had fallen to $23 \mathrm{ng} / \mathrm{mL}$ four days later (a decrease of $69 \%$ ) which motivated gradually increasing the dose to $225 \mathrm{mg}$ /day (Fig. 1).

Finally, the patient recovered and therapeutic cyclosporine levels were achieved.

\section{Discussion}

This was a case of an extremely rare joint infection due to Mycobacterium malmoense in a kidney transplant recipient with multiple drug interaction.

Rifampicin is a potent inducer of cytochrome p450 3A4 enzyme and P-glycoprotein transport system, and can affect the absorption and the metabolism of cyclosporine [2]. There is a considerable number of reports about the coadministration of rifampicin and cyclosporine that confirm a very marked fall in Cyclosporine $\mathrm{C}$; ; also, levels may rise to toxic proportions within two weeks after withdrawal of the antituberculous drug [2]. Recent studies report that cyclosporine dosage has had to be increased 3 to 5 times to keep blood concentrations within therapeutic range $[2,3]$. In this patient the increase required was smaller, probably because the introduction of clarithromycin. Macrolides inhibit cyclosporine metabolism in the liver, catalyzed by cytochrome $\mathrm{p} 450$ $3 \mathrm{~A} 4$. Clarithromycin is structurally similar to erythromycin and it also appears to increase gut absorption of cyclosporine by inhibiting intestinal wall metabolism. In some reported cases, the trough blood cyclosporine levels of kidney transplant patients doubled or tripled on receiving clarithromycin, within 3 - 8 days of starting the drug. As a result, a mean $30 \%$ reduction in the cyclosporine dosage and careful monitoring of concentrations may be necessary [4]. Sometimes, interaction with clarithromyicin may be observed as late as 14 days after withdrawal.

Isoniazide [2, 5], pirazinamide [5] and/or ethambutol [5] do not normally interact with cyclosporine and therefore produce no relevant clinical and blood concentration changes.

In this case there was a balance between induction and inhibition in cyclosporine metabolism, due to the co-administration of rifampicin and clarithromycin, which was lost when the rifampicin was withdrawn. Cyclosporine $\mathrm{C} 0$ showed a threefold increase within 15 days. Renal function worsened as a consequence of the increased level and it was necessary to decrease cyclosporine dosage three times.

The renal function improved within 6 weeks but never recovered pre-treatment values.

One year later when clarithromycin was withdrawn, the C0 decreased by $69 \%$ when the inhibitor effect disappeared.

Finally, if rifampicin and clarithromycin have the same metabolic pathway by cytochrome p450, there may be an interaction between these drugs. Several small studies [6-8] and some case reports $[9,10]$ have suggested that rifamycin derivates may significantly decrease serum clarithromycin concentrations. Drug interactions between rifabutin and clarithromycin include both induction and inhibition. This bidirectional interaction was studied in clinically stable HIVinfected volunteers. The authors reported changes in Cmax and AUC of the two drugs during the first days of starting treatment with rifampicin in a clarithromycin group (with 
decreases of $44 \%$ AUC and $41 \%$ Cmax) and with clarithromycin in a rifampicin group (with increases of $99 \%$ AUC and $69 \% \mathrm{Cmax}$ ). The number of adverse drug reactions also increased.

\section{Conclusions}

The interactions between antibiotic treatment and cyclosporine therapy should be observed closely, requiring level determinations and dosing changes two to three times per week as from the first day of starting the concurrent treatment. This may help to avoid severe adverse drug effects like nephrotoxicity and to achieve therapeutic goals.

\section{Conflicts of Interest}

The authors should declare any conflict of interests related to this manuscript.

\section{Grant Support}

None.

\section{References}

1. Lo A, Burckart GJ. P-glycoprotein and drug therapy in organ transplantation. J Clin Pharmacol. 1999;39(10):9951005.

2. Campana C, Regazzi MB, Buggia I, Molinaro M. Clinically significant drug interactions with cyclosporin. An update. Clin Pharmacokinet. 1996;30(2):141-179.
3. Aguado JM, Herrero JA, Gavalda J, Torre-Cisneros J, Blanes M, Rufi G, Moreno A, et al. Clinical presentation and outcome of tuberculosis in kidney, liver, and heart transplant recipients in Spain. Spanish Transplantation Infection Study Group, GESITRA. Transplantation. 1997;63(9):1278-1286.

4. Rodvold KA. Clinical pharmacokinetics of clarithromycin. Clin Pharmacokinet. 1999;37(5):385-398.

5. Kim YH, Yoon YR, Kim YW, Shin JG, Cha IJ. Effects of rifampin on cyclosporine disposition in kidney recipients with tuberculosis. Transplant Proc. 1998;30(7):35703572.

6. Pai MP, Graci DM, Amsden GW. Macrolide drug interactions: an update. Ann Pharmacother. 2000;34(4):495513.

7. Sadaba B, Lopez de Ocariz A, Azanza JR, Quiroga J, Cienfuegos JA. Concurrent clarithromycin and cyclosporin A treatment. J Antimicrob Chemother. 1998;42(3):393-395.

8. Yamamoto F, Harada S, Mitsuyama T, Harada Y, Kitahara Y, Yoshida M, Nakanishi Y. Concentration of clarithromycin and 14-R-hydroxy-clarithromycin in plasma of patients with Mycobacterium avium complex infection, before and after the addition of rifampicin. Jpn J Antibiot. 2004;57(1):124-133.

9. Plemmons RM, McAllister CK, Garces MC, Ward RL. Osteomyelitis due to Mycobacterium haemophilum in a cardiac transplant patient: case report and analysis of interactions among clarithromycin, rifampin, and cyclosporine. Clin Infect Dis. 1997;24(5):995-997.

10. Bossert T, Bittner HB, Richter M, Rahmel A, Barten M, Gummert JF, Mohr FW. Successful management of two heart transplant recipients with mycobacterial pulmonary infections. Ann Thorac Surg. 2005;80(2):719-721. 